\title{
Effect of WC-Ni Powder Composition and Preparation on Cold Spray Performance
}

\author{
Joseph Heelan ${ }^{1, *}$, Sean M. Langan ${ }^{1}$, Caitlin Walde ${ }^{1}$, Aaron Nardi ${ }^{2}$, Matthew Siopis ${ }^{2}$, \\ Robert Barth ${ }^{3}$, Timothy Landry ${ }^{3}$ and Aaron Birt ${ }^{1}$ \\ 1 Solvus Global, Worcester, MA 01605, USA; sean.langan@solvusglobal.com (S.M.L.); \\ caitlin.walde@solvusglobal.com (C.W.); aaron.birt@solvusglobal.com (A.B.) \\ 2 US Army Research Laboratory, Aberdeen Proving Ground, Aberdeen, MD 21005, USA; \\ aaron.t.nardi.civ@mail.mil (A.N.); matthew.j.siopis.civ@mail.mil (M.S.) \\ 3 Raytheon Technologies Research Center, East Hartford, CT 06108, USA; robert.barth@rtx.com (R.B.); \\ timothy.landry@rtx.com (T.L.) \\ * Correspondence: joseph.heelan@solvusglobal.com
}

Received: 14 November 2020; Accepted: 4 December 2020; Published: 8 December 2020

Abstract: Toxic metal reduction is at the forefront of many design considerations today; additive manufacturing has the ability to combine materials in ways other traditional processes cannot and has the potential to offer unique solutions to reduce hazardous materials needed in manufacturing. Tungsten carbide (WC) has been used as a substitute in wear applications where toxic processes are traditionally utilized, but it can be difficult to deposit high-quality, hard and durable coatings. Additionally, there is a need to apply WC coatings on surfaces not feasible with the current processes. Cold spray, a solid-state directed powder deposition process, is effective at depositing carbides, though powders must be thoughtfully designed to achieve desired mechanical properties. In this study, WC was investigated as a hard chrome alternative for wear applications. Various blend ratios and preparation methods were evaluated as feedstock powder and then sprayed. Feedstock characteristics were compared to cold spray performance. Cold spray consolidations were evaluated for coating porosity and hardness. It was found that when powder make-up and composition were optimized, a high-hardness and low-porosity material was made that will contribute to the reduction in dependency of $\mathrm{Cr}$ in wear-facing components.

Keywords: tungsten carbide; nickel; cold spray; wear; hardness; deposition efficiency

\section{Introduction}

For many engineering applications, wear is inevitable and requires specific materials to counteract it. In addition to its damaging nature, wear is expensive, accounting for $1 \%-4 \%$ of an industrialized country's GNP [1,2]. There are four primary modes for how materials are worn: abrasive, corrosive, adhesive, and fatigue wear [3]. There are a variety of mechanisms for resisting this damage. Many materials have hard secondary phases that reinforce the softer primary phase, increasing the wear tolerance of the material [4]. External lubrication is a classic method of reducing wear damage to a material, and increasingly, materials are being designed that are "self-lubricating". Several mechanisms exist for self-lubrication, including embedding solid lubricants into the base material or coating the base substrate with a layer of material, such as diamond-like carbon [4], and while these mechanisms are not examined in this current study, they remain important. Mechanochemical processes can produce tribofilms or polymerize surface compounds when exposed to wear, which can have beneficial wear characteristics [5].

One of the most prevalent wear coatings in industry has traditionally been chromium plating. Hard-chrome plating possesses high hardness, in excess of $800 \mathrm{HV}$, and has good wear performance in 
a wide variety of material combinations [6,7]. These plated coatings have high resistance to corrosion, and are good in cases of sliding wear, especially in corrosive environments [7]. While chromium plating has good performance, the process is harmful to human health as well as the environment. The chrome plating process uses and emits hexavalent chrome, a known carcinogen, and requires sulfuric acid as well as toxic electrolytes [8,9]. Hexavalent chromium can enter water and soil through industrial, municipal, and agricultural waste and impact the health of animals and plants [10]. This has led to increasing efforts in recent years to find chrome alternatives, such as thermo-chemical chromizing [11]. This chromizing is done at high temperatures and, as such, lower temperature alternatives are required. One such alternative is a tungsten carbide-based cermet designed specifically for cold spray applications. This system has a hardwearing WC phase, with a more ductile nickel-based phase that acts as the binding agent. It is similar to many chrome carbide-based systems, such as chrome-carbide nickel [12,13] and chrome-carbide nickel chromium [14,15]. If engineered correctly, a tungsten carbide-based coating can be used as an alternative to hard-chrome coatings for hydraulic cylinders, gas turbine pistons, and localized repairs for the Department of Defense (DoD), to name a few [16-18].

Cermet materials are frequently deposited via cold spray, a solid-state, directed powder deposition process. When the powder feedstock is designed correctly, cold sprayed cermets can produce coatings with a hardness that can approach or exceed that of hard-chrome coatings and, if properly designed, can exceed the wear and toughness of electrodeposited chromium [18]. Cold spray is capable of depositing a wide range of materials, from metals, such as titanium and aluminum alloys, and cermets to refractories, such as tungsten and tantalum, and high entropy alloys [19-25]. During deposition, particles are entrained in a gas stream, accelerated to supersonic velocities with a converging-diverging nozzle, and directed at a substrate where the particles plastically deform, adhere, and build up layers. The gas reaches velocities between 300 and $1500 \mathrm{~m} / \mathrm{s}$ depending on operating conditions (temperature, pressure, nozzle design, and standoff distance from surface). The powder velocity is determined by the gas, system, and powder characteristics [26]. These high velocities provide enough energy during impact to cause severe plastic deformation and metallurgical bonding between individual particles while still maintaining an overall low temperature [26].

Unlike high-temperature fabrication techniques (e.g., plasma spraying, high-velocity oxygen fuel (HVOF), welding, etc.), during cold spray, the feedstock powder remains in the solid state; this leads to retention of feedstock microstructural features in the final part. Additionally, the cold spray process enables the consolidation of powders into coatings that are fully dense, does not increase the oxygen content, has no heat-affected zone, and has the ability to form compressive residual stresses at the surface, which increases the fracture resistance of the material system [20,27-29].

The inherent problem with WC-based materials is it can be difficult to achieve coatings with an optimized combination of hardness, toughness, and quality when cold sprayed using powders that have not been designed for the process. In cold spray, a ductile binding agent is required as an additive to initiate plastic deformation and bonding. This is true in some thermal spray processes as well, but proper distribution, size, and composition of this binder is the key to balancing hardness, toughness, and quality. For these types of cermets, increasing the volume percentage of binder increases the deposition efficiency but decreases the hardness of the material. With the competing need for a high-hardness material to achieve good wear properties (low binder content) and the need for high deposition efficiency, toughness, and ease of spraying (high binder content), there is the opportunity for an optimization to find an ideal powder formula.

This is further complicated by the fact that the powder manufacturing process also impacts the quality of the deposition and must be evaluated and accounted for [29]. Low-pressure cold spray of WC-Ni metal matrix composites has been studied in the literature. Lioma et al. studied WC and WC-12Co powders mechanically mixed with $\mathrm{Ni}$ at varying ratios and achieved a maximum hardness of $403 \mathrm{HV}$ [30]. Nunthavarawong et al. optimized the powder feed rate for a mechanically blended $5 \% \mathrm{Ni}-\mathrm{WC}$ blend and achieved a maximum hardness of $2.56 \mathrm{GPa}(261 \mathrm{HV})$ [31]. Melendez et al. 
evaluated mechanically mixed WC-12Co with Ni powder at varying ratios and showed that wear rate decreased and hardness increased with increase in WC content, achieving a maximum hardness of $520 \mathrm{HV}$ [32]. Alidokht et al. showed that additions of WC to low-pressure Ni cold spray decreased deposition efficiency and increased hardness [33]. Additionally, adding WC to the Ni improved wear rates, which was attributed to the fragmentation and redistribution of the WC particles during wear. Similarly, Melendez et al. studied various compositions of mechanically blended WC-12Co with Ni powder and found that hardness increased with increasing WC content [34]. While dense coatings can be achieved, the hardness of the deposits is lower than those obtained via HVOF. High-pressure cold spray can achieve higher particle velocities, which increases the deformation and strain hardening of the particles during deposition, ultimately leading to higher-hardness deposits when compared to low-pressure cold spray.

In the current study, a WC-based powder designed to optimize particle surface characteristics is further developed. Unlike traditional agglomerated particles which have soft-phase materials distributed equally around and within the core particle, the concentration of soft phase was deliberately made higher at the surface of the core particle. By engineering the composition and location of this soft phase, a powder could be developed that maximized both deposit hardness and coating quality when deposited using cold spray. This material would be used to counteract abrasive, erosive, and oxidation/corrosive wear as a metal matrix composite with a well-bonded hard phase designed to wear away and not fall out. The objective of this work was to (1) quantify how small changes in powder composition affects mechanical properties of the deposit and (2) to investigate how the geometric distribution of the ductile phase around the particle agglomerate impacts coating quality.

\section{Materials and Methods}

\subsection{Powder}

Two types of tungsten carbide-based powders were evaluated to investigate how modifying the surface characteristics of hard-phase particles affects coating quality when cold sprayed. A decorated WC-Co + Ni powder was used as the primary material; it was composed of a spray-dried and sintered, hard tungsten carbide-cobalt core particle $(5-30 \mu \mathrm{m})$ cladded by softer and finer nickel particles $(2-8 \mu \mathrm{m})$. The core particle contained tungsten carbide, with $12 \mathrm{wt} . \%$ cobalt used as the binding agent during spray-dry agglomeration and sintering. Varying amounts of nickel were cladded to the surface of these core particles which were evaluated as part of this study; Table 1 shows a schematic of this. The process used to clad nickel to the WC-Co particles was a technique known as granulation. During granulation, the softer particles were attached to the harder particles via a solid nickel bridge connecting the hard and soft phases. Custom $\beta$-trial decorated WC-Co $+x$ Ni powder iterations were initially provided to analyze how modifying nickel composition affects coating quality and hardness. Powders evaluated contained 18, 24, 30, and $36 \mathrm{wt} . \%$ nickel and were produced at a laboratory scale.

Standard, commercially-available decorated $18 \mathrm{Ni}-10 \mathrm{Co}-72 \mathrm{WC}$ was also evaluated. This powder was tested against a blended powder having the same composition as the decorated material, but soft phase and hard phase constituents were not physically bonded. Approximately $400 \mathrm{~g}$ of each powder was provided, and each powder was characterized prior to cold spray trials. The configuration of each powder tested is defined in Table 1.

\subsection{Powder Characterization}

A critical component to cold spray production is having a feedstock supply chain that conforms to strict quality standards. Characterization was performed to evaluate powder properties, such as size distribution, morphology, flowability, and powder compaction. An explanation of each test conducted is described as follows. 
Table 1. Composition and configuration of evaluated powders.

\begin{tabular}{|c|c|c|c|c|c|}
\hline Powder Type & Condition & Nickel (wt.\%) & $\begin{array}{l}\text { Soft/Hard Phase } \\
\text { Configuration-Schematic }\end{array}$ & $\begin{array}{c}\text { Soft/Hard Phase } \\
\text { Configuration-SEM }\end{array}$ & Description \\
\hline Decorated & $\beta$-trial & 18 & & & \\
\hline Decorated & $\beta$-trial & 24 & & & $\begin{array}{c}\text { Finer, soft } \\
\text { phase bonded }\end{array}$ \\
\hline Decorated & $\beta$-trial & 30 & & & to the surface \\
\hline Decorated & $\beta$-trial & 36 & & & $\begin{array}{l}\text { of the larger, } \\
\text { hard phase }\end{array}$ \\
\hline Decorated & Standard & 18 & & & \\
\hline Blended & Custom & 18 & & & $\begin{array}{l}\text { Blended hard } \\
\text { and soft phase, } \\
\text { no adhesion }\end{array}$ \\
\hline
\end{tabular}

\subsubsection{Particle Size Distribution}

Particle size distribution is typically reported as $d_{10}, d_{50}$, and $d_{90}$ values, which represents the particle diameter of the 10th, 50th, and 90th volume percentiles. Size distribution is a widely-used quality metric but also has other implications for cold spray. Because powder particles remain in the solid state during cold spray, they require a certain energy in order to deform and adhere to the substrate. This minimum energy is related to the particle size, as different size particles achieve different velocities in the gas stream. For repeatability and quality, it is important to understand the size distribution of a given powder to be used in cold spray. In this evaluation, $d_{10}, d_{50}$, and $d_{90}$ values were determined via a static image analysis method following ISO 13322-1 [35].

\subsubsection{Density}

Density of a powder is reported three ways; bulk density, tapped density, and the ratio between the two (Hausner ratio). Bulk density of a powder is determined by measuring the volume and mass of powder in the untapped condition in a graduated cylinder. The powder is then tapped to compact the powder and encourage settling and optimal packing density. This new volume is then measured, and the ratio between them is reported as the Hausner ratio (tapped/untapped). Hausner ratios are generally greater than 1.0; close to 1.0 indicates little to no settling when tapped, while larger numbers indicate high degrees of settling when tapped. This is an important metric for quality control as well as for optimizing cold spray powder feeder conditions. In a cold spray powder feeder, the tendency of a powder to compact plays a role in the powder feed rate and vibration (if any) used. The density of a powder can change with size distribution or contamination, so measuring this provides an extra layer of quality control.

\subsubsection{Flowability}

Flowability of each powder was measured using the Carney funnel as per ASTM B964-166 [36]. This method measures the flow rate for a given mass of powder through a standard orifice. A given powder was evaluated 3 times and the average for flow rate in $\mathrm{g} / \mathrm{s}$ is reported here.

\subsubsection{Impact}

Compaction of a powder was measured by using a single, rapidly applied force to compact a small, known volume of powder. After the load was applied, the powder formed a compacted puck, and the mass and thickness of these pucks were measured. The percent of mass compacted (mass of puck after compaction divided by input mass) was calculated. Together with puck thickness, this metric can provide an indication of a powder's ability to cohere and bond under a given load. In this evaluation, these metrics are compared to deposition efficiency. 


\subsubsection{Electron Microscopy}

The morphology of each powder condition was evaluated visually using a scanning electron microscope (SEM) (Topcon, Tokyo, Japan) and composition of deposits was measured using energy-dispersive X-ray spectroscopy (EDS) (EDAX, Mahwah, NJ, USA). Additionally, an FEI Quanta 600 (Thermo Fischer Scientific, Waltham, MA, USA) was used to detect both secondary and backscattered electrons. Images were taken at $20 \mathrm{kV}$.

\subsection{Cold Spray Consolidation}

Figure 1 shows a diagram of the cold spray process. Powders were cold sprayed using a Gen III cold spray system (VRC Metal Systems, Box Elder, SD, USA). Powders were sprayed at varying gas pressures ranging from 35 to 50 bar and at a gas temperature of approximately $600-700{ }^{\circ} \mathrm{C}$. When higher-pressure conditions were applied, a 4-foot section of a pre-heater gas line was installed to drive up the temperature. Without the pre-heater gas line, gas temperature fell below $600^{\circ} \mathrm{C}$ at pressures greater than 45 bar. The installed pre-heater line enabled a gas temperature of $650{ }^{\circ} \mathrm{C}$ to be reached. Bottled pure helium was used as the carrier gas. Two commercially available cold spray nozzles were utilized; the VRC mini-ID carbide nozzle $(1.57-\mathrm{mm}$ throat diameter $\times 2.24-\mathrm{mm}$ exit diameter $\times$ 19.05-mm expanding section) and the VRC NZZL0082 carbide nozzle (1.47-mm throat diameter $\times$ 2.41-mm exit diameter $\times 73.15$-mm expanding section). The VRC mini-ID carbide nozzle, used to coat bores down to $45 \mathrm{~mm}$ in diameter, and a VRC NZZL0082 carbide nozzle, used to coat bores down to $100 \mathrm{~mm}$ in diameter, were utilized for spray trials. The working distance, raster speed, and powder feed rate were $13 \mathrm{~mm}, 200 \mathrm{~mm} / \mathrm{s}$, and 4 rotations per minute (RPM), respectively. Fifty grams of powder was loaded into the powder feeder at a time and was sprayed onto both $76 \times 51 \times 6 \mathrm{~mm}^{3}$ 1018 substrate material and 2.4-mm thick, steel Almen strips, type C, grade 2. Deposition efficiency and deposit thickness were recorded for each sample. The thickness of the coating ranged from 0.25 to $0.50 \mathrm{~mm}$.

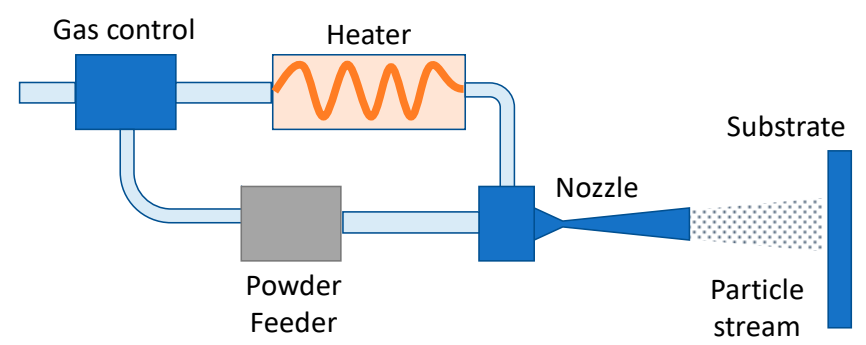

Figure 1. Diagram of the cold spray process.

\subsection{Deposit Evaluation}

After consolidation, specimens were cross-sectioned perpendicular to the raster direction and subsequently mounted and polished. Then, 240 -grit $\mathrm{Si}-\mathrm{C}$ grinding paper was used to establish a single plane on the sample. Once a level surface was achieved, samples were ground by 320-, 600-, 800-, and 1200-grit Si-C grinding paper. For polishing, $6 \mu \mathrm{m}$ polycrystalline diamond suspension followed by $1 \mu \mathrm{m}$ polycrystalline diamond suspension and lubricant were used on a woven low-napped polishing pad with colloidal silica as the finishing step. Optical microscopy was performed to evaluate the coating at $20 \times$ and $40 \times$ magnification. An ideal deposit would show a dense coating with no sign of cracking, porosity, or delamination from the substrate material. Micrographs were taken at multiple locations along the coating of the specimen.

Polished cross-sections were additionally indented to measure the Vickers hardness of the coating (Wilson VH3300 Automatic Hardness Tester, Buehler, Lake Bluff, IL, USA). Six indentations were made at random locations along the center of the coating. A 500-g load was applied to generate the 
indentation with a 10-s dwell time. Microhardness indentations were analyzed at 100× magnification. The average of the six data points was recorded.

\section{Results and Discussion}

\subsection{Powder Characterization}

Tables 2 and 3 show powder characterization data, including particle size distribution, Carney flow rates, bulk and tapped density, and percent mass compacted metrics for the evaluated powders. Particle size distribution (PSD) is reported as $d_{10}, d_{50}$, and $d_{90}$ values. It can be seen that the PSD skews larger with increasing amounts of nickel due to particle agglomeration. Additionally, the blended $18 \mathrm{wt} . \% \mathrm{Ni}$ is smaller than its decorated counterpart. All PSDs indicate a powder that is compatible with cold spray.

Table 2. Particle size distribution of evaluated powders.

\begin{tabular}{cccccc}
\hline Powder Manufacturing Method & Condition & Nickel $(\mathbf{w t} . \mathbf{\%})$ & $\boldsymbol{d}_{\mathbf{1 0}}(\boldsymbol{\mu \mathbf { m } )}$ & $\boldsymbol{d}_{\mathbf{5 0}}(\boldsymbol{\mu \mathbf { m } )}$ & $\boldsymbol{d}_{\mathbf{9 0}}(\boldsymbol{\mu m})$ \\
\hline Decorated & Standard & 18 & 15.9 & 27.3 & 51.1 \\
Decorated & $\beta$-trial & 18 & 16.5 & 25.1 & 47.9 \\
Decorated & $\beta$-trial & 24 & 16.8 & 27.0 & 63.5 \\
Decorated & $\beta$-trial & 30 & 17.8 & 30.8 & 74.5 \\
Decorated & $\beta$-trial & 36 & 19.4 & 37.0 & 79.7 \\
Blended & Custom & 18 & 12.0 & 20.0 & 30.7 \\
\hline
\end{tabular}

Table 3. Characterization data of evaluated powders.

\begin{tabular}{cccccccc}
\hline $\begin{array}{c}\text { Powder } \\
\text { Manufacturing } \\
\text { Method }\end{array}$ & Condition & Nickel (wt.\%) & $\begin{array}{c}\text { Carney Flow } \\
\text { Rate } \mathbf{( g / s )}\end{array}$ & $\begin{array}{c}\text { Bulk Density } \\
\text { (g/mL) }\end{array}$ & $\begin{array}{c}\text { Tapped } \\
\text { Density } \\
\text { (g/mL) }\end{array}$ & $\begin{array}{c}\text { Hausner } \\
\text { Ratio }\end{array}$ & $\begin{array}{c}\text { Percent Mass } \\
\text { Compacted } \\
\mathbf{( \% )}\end{array}$ \\
\hline Decorated & Standard & 18 & 12.5 & 3.33 & 4.13 & 1.24 \\
Decorated & $\beta$-trial & 18 & 19 & 4.23 & 5.25 & 1.24 \\
Decorated & $\beta$-trial & 24 & 17 & 4.39 & 5.68 & 1.29 \\
Decorated & $\beta$-trial & 30 & 13.8 & 3.68 & 4.74 & 1.29 \\
Decorated & $\beta$-trial & 36 & 15.8 & 3.71 & 4.8 & 1.29 & 79.7 \\
Blended & Custom & 18 & 15.4 & 4.85 & 5.55 & 1.15 \\
\hline
\end{tabular}

Bulk and tapped density were measured for each powder to show how nickel content and manufacturing method affect physical properties. It was observed that increasing nickel content reduced density due to a lower tungsten carbide concentration. The blended powder is slightly denser, in both the bulk and tapped evaluations, than the decorated powder of the same nickel content due to a change in the particle size and shape. Table 3 also shows the Carney flow rates for each powder; while there is some variation between the powders, there is no correlation to nickel concentration. All powder flowed smoothly through the Carney funnel and rates ranged from 12.5 to $19.0 \mathrm{~g} / \mathrm{s}$.

Figure 2 shows percent mass compaction as a function of the nickel concentration for all powders evaluated. It was observed that adding nickel improves the compaction efficiency of the WC-Co. It can also be seen that the blended powder has lower compaction efficiency than its decorated counterpart of the same nickel composition. From these data, it can be hypothesized that the addition of nickel on the surface of the core particle will improve the deposition efficiency of the WC-Co during cold spray consolidation. 


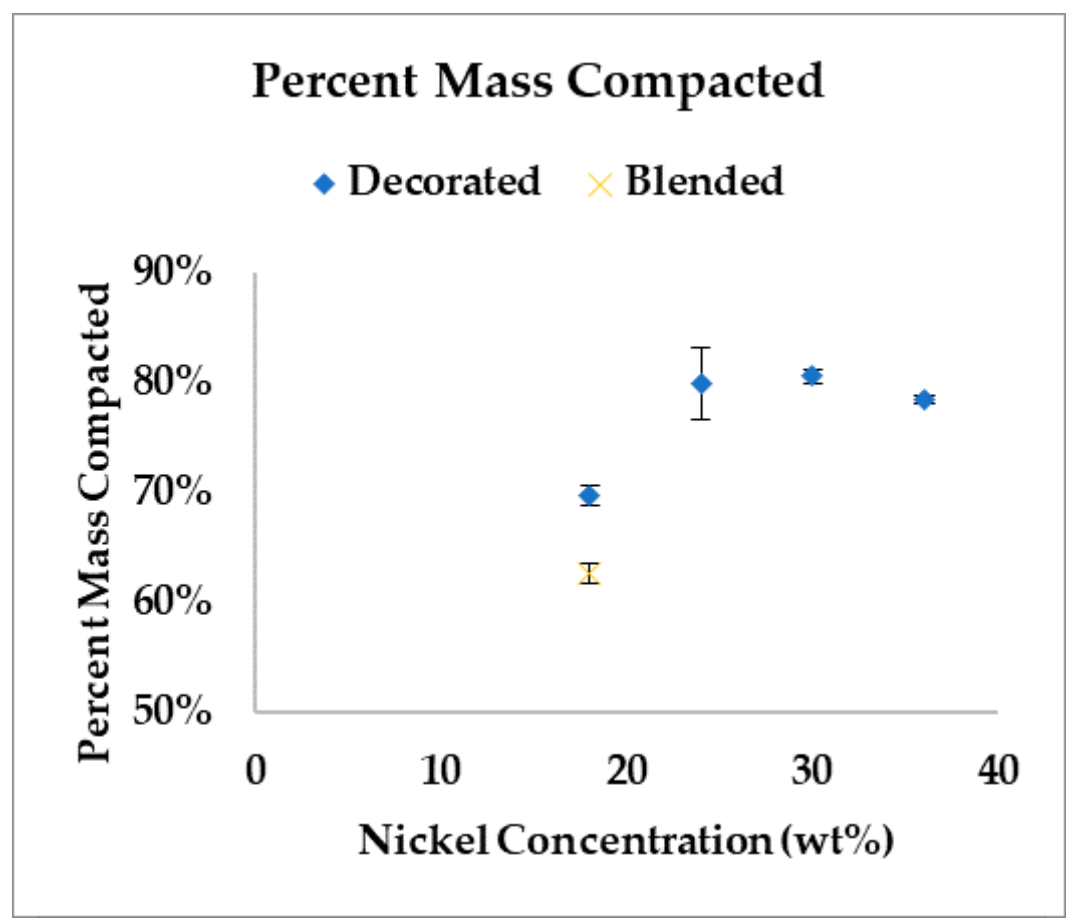

Figure 2. Percent mass compacted during impact testing. Error bars indicate +1 standard deviation.

\subsection{Cold Spray Evaluation}

\subsubsection{Compositional Impact Assessment}

The hardness and deposition efficiency of cold sprayed specimens using $\beta$-trial decorated powders with varying nickel concentrations are shown in Table 4 . The nickel concentration of the powder was varied between $18 \%-36 \%$ to evaluate how changing the composition affects coating quality and mechanical properties. Measurements were collected for cold spray trials that used both the VRC mini-ID nozzle and VRC NZZL0082 nozzle. Hardness results are higher for materials sprayed using the VRC NZZL0082 nozzle compared to the VRC mini-ID nozzle due to the longer nozzle length allowing for longer acceleration times, thereby maximizing the particle impact velocity. The highest recorded average hardness was $727 \mathrm{HV}$ which was sprayed using the VRC NZZL0082 with $18 \mathrm{wt} . \% \mathrm{Ni}$. Hardness decreased as nickel concentration increased. The lowest recorded average hardness was 417 $\mathrm{HV}$ and was sprayed using the VRC mini-ID nozzle with $36 \mathrm{wt} . \% \mathrm{Ni}$. The deposition efficiency ranged from 43 to $26 \%$ and 35 to $21 \%$ for powders cold sprayed with the VRC NZZL0082 nozzle and VRC mini-ID nozzle, respectively. In general, deposition efficiency decreased as nickel content was reduced. One outlier to this trend was the $24 \%$ Ni powder, which had an equivalent deposition efficiency compared to the $18 \%$ Ni when sprayed with the VRC NZZL0082 nozzle and a lower deposition efficiency compared to the $18 \% \mathrm{Ni}$ when sprayed with the VRC mini-ID nozzle. Additionally, the deposition efficiency was consistently higher with the VRC NZZL0082 nozzle, except for the $18 \% \mathrm{Ni}$. A possible explanation for these deviations from the trend may be attributed to an uneven distribution of nickel on the surface of tungsten carbide particles, where certain particles were nickel-rich and others had limited or no bonded nickel, which could abrade the coating when sprayed. The cause for this uneven distribution may be due to the laboratory-scale processing procedure for synthesizing $\beta$-trial powders. This inefficiency can be corrected when using production-scale equipment for agglomerating powder that standardizes the cladding process. 
Table 4. Deposit hardness and deposition efficiency for varying nickel compositions for $\beta$-decorated powders.

\begin{tabular}{|c|c|c|c|c|c|}
\hline Characteristic & Nozzle & 36 wt.\% Ni & 30 wt. $\% \mathrm{Ni}$ & 24 wt.\% Ni & 18 wt. $\% \mathrm{Ni}$ \\
\hline \multirow{2}{*}{$\begin{array}{l}\text { Average } \\
\text { Hardness } \\
\text { (Vickers) }\end{array}$} & $\begin{array}{c}\text { VRC NZZL0082 } \\
(1.47 \mathrm{~mm} \times 2.41 \mathrm{~mm} \times \\
73.15 \mathrm{~mm})\end{array}$ & $539 \mathrm{HV}$ & $511 \mathrm{HV}$ & $559 \mathrm{HV}$ & $727 \mathrm{HV}$ \\
\hline & $\begin{array}{l}\text { VRC Mini-ID nozzle } \\
(1.57 \mathrm{~mm} \times 2.24 \mathrm{~mm} \times \\
19.05 \mathrm{~mm})\end{array}$ & $417 \mathrm{HV}$ & $456 \mathrm{HV}$ & $456 \mathrm{HV}$ & $517 \mathrm{HV}$ \\
\hline \multirow{2}{*}{$\begin{array}{l}\text { Deposition } \\
\text { Efficiency }\end{array}$} & $\begin{array}{c}\text { VRC NZZL0082 } \\
(1.47 \mathrm{~mm} \times 2.41 \mathrm{~mm} \times \\
73.15 \mathrm{~mm})\end{array}$ & $43 \%$ & $35 \%$ & $26 \%$ & $26 \%$ \\
\hline & $\begin{array}{l}\text { VRC Mini-ID nozzle } \\
(1.57 \mathrm{~mm} \times 2.24 \mathrm{~mm} \times \\
19.05 \mathrm{~mm})\end{array}$ & $35 \%$ & $29 \%$ & $21 \%$ & $29 \%$ \\
\hline
\end{tabular}

Cross-sections of each coating at varying nickel concentrations are shown in Figures 3 and 4. For both figures, the same four powders with different nickel contents were used; Figure 3 was generated using powders cold sprayed with the VRC NZZL0082 nozzle and Figure 4 was generated using powders cold sprayed with the VRC Mini ID nozzle. In each optical micrograph, a two-phase deposit is evident. The lighter areas correspond to regions of high nickel content and the darker areas correspond to regions of high tungsten carbide content. Both the 36 and $30 \mathrm{wt} . \%$ nickel coupons resulted in thicker coatings with minimal porosity or particle pull-out observed. A dense and slightly thinner coating was also observed for the coupons containing the 24 and $18 \mathrm{wt} . \%$ nickel. With the 18 wt.\% nickel, one instance of cracking in the bottom section of the coating is shown in Figure 3. Additionally, some delamination from the substrate was observed for the $18 \mathrm{wt} . \%$ nickel iteration when evaluating additional locations along the cross-section. Delamination can be remedied by either optimizing spray conditions or incorporating a bond coat layer as a pre-processing step before cold spraying the primary $18 \mathrm{Ni}-10 \mathrm{Co}-72 \mathrm{WC}$ build-up layers. This is especially important when spraying onto harder substrates.
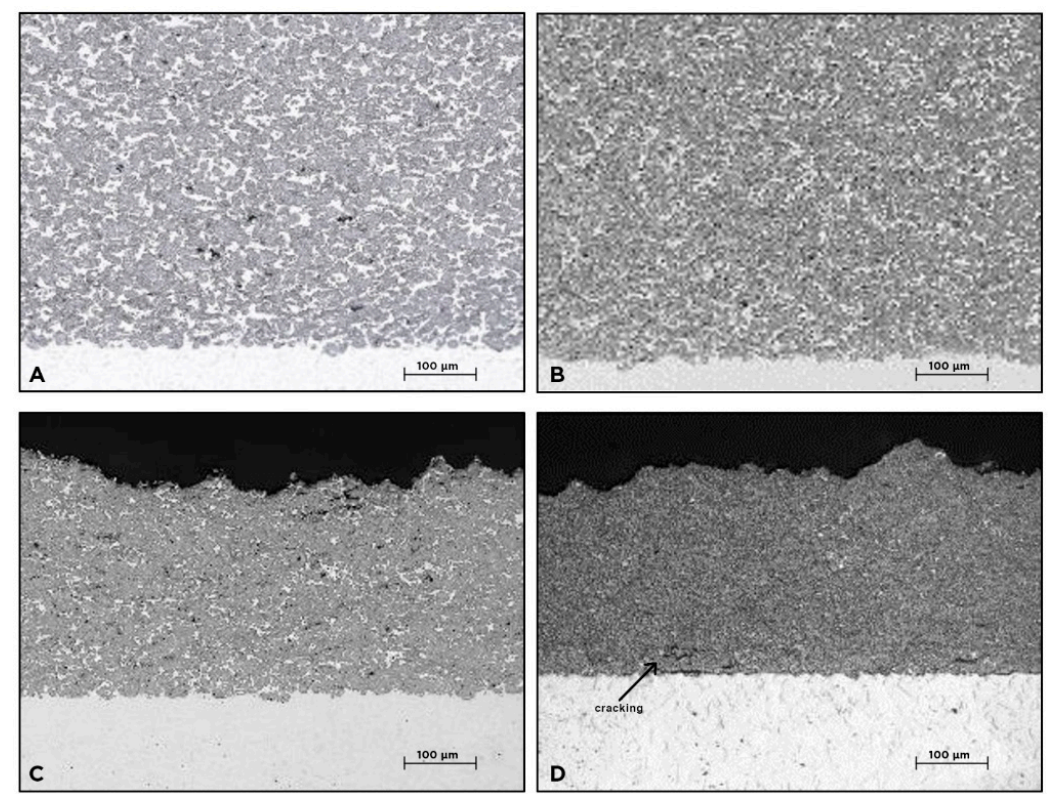

Figure 3. Cross-sections of deposits cold sprayed using different concentrations of nickel in the synthesized powder and the VRC NZZL0082 nozzle; (A) 36 wt.\% Ni deposit, (B) 30 wt.\% Ni deposit, (C) 24 wt.\% Ni deposit, (D) 18 wt.\% Ni deposit. 

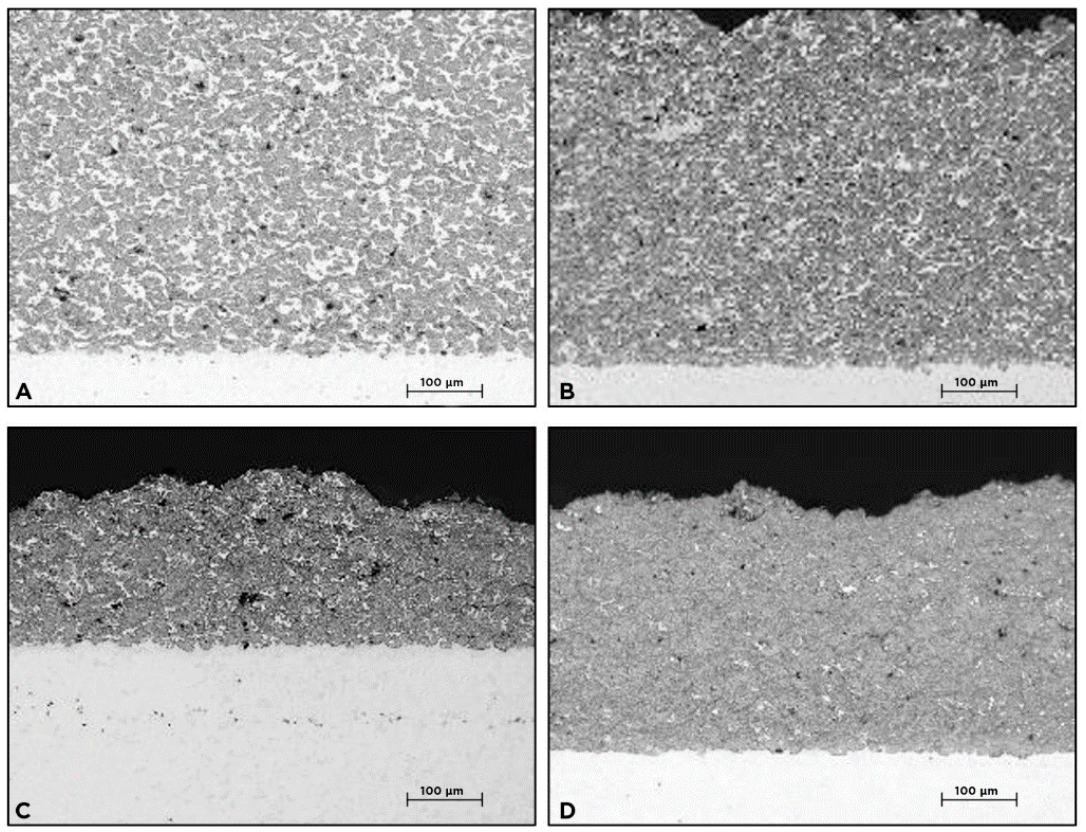

Figure 4. Cross-sections of deposits cold sprayed using different concentrations of nickel in the synthesized powder and the VRC mini-ID nozzle; (A) 36 wt.\% Ni deposit, (B) 30 wt.\% Ni deposit, (C) 24 wt.\% Ni deposit, (D) 18 wt.\% Ni deposit.

Nickel cladded to the surface of the WC-Co particles enables enhanced adhesion during cold spray consolidation. Conventional WC-Co powders in a spray-dried formulation must be modified to add nickel targeted to a certain morphology, such as a coating. When the nickel concentration of the feedstock powder is maximized, the toughness of the coating increases [19]. By having a more ductile binding powder, less powder bounces off the substrate during the cold spray process, which was validated by the higher deposition efficiency observed in the $30+w t . \%$ nickel decorated powder trials. The downside to using a more ductile binding powder is that hardness is sacrificed. There is a balance between achieving a dense coating with limited cracking and maintaining a high-enough hardness for wear and impact resistance. When high hardness is desired, such as hard-chrome replacement applications, lowering the nickel content is critical. The hardness data shown here validates the claim that when material process optimization is performed, cold sprayed tungsten carbide-based materials can compete with coatings produced using hard-chrome plating. In particular, for an application where a slightly reduced hardness is acceptable (727 HV-decorated tungsten carbide-based cold spray coating vs. $800+\mathrm{HV}$-hard-chrome coating), cold spray using decorated tungsten carbide materials becomes a suitable means for eliminating hexavalent chromium from the production process. When more ductility is required, such as in nitrogen cold spray applications, adding more nickel will result in improved bonding. Future work will involve (1) cold spraying high nickel content $\beta$-decorated powders with nitrogen as the carrier gas and (2) analyzing how modifying the internal metal content of spray-dried and sintered core particles in combination with nickel cladding affects coating performance when cold sprayed.

\subsubsection{Geometric Configuration Assessment}

Tungsten carbide plus nickel powders were synthesized via two methods and consolidated into coatings using the cold spray process, then evaluated for microhardness and coating quality. The intent of this side-by-side comparison was to investigate which processing technique worked best for creating dense coatings with a maximized hardness. Hardness measurements and micrographs for deposits manufactured using decorated $18 \mathrm{Ni}-10 \mathrm{Co}-72 \mathrm{WC}$ powder and a blended powder of the same composition are shown in Table 5 and Figure 5. Data shows that a higher coating hardness can 
be achieved by using the decorated $18 \mathrm{Ni}-10 \mathrm{Co}-72 \mathrm{WC}$ powder compared to conventional methods. Optical micrographs show the presence of both hard-phase tungsten carbide in the darker regions and soft-phase nickel/cobalt in the lighter regions. A dense coating with no indication of cracking is observed for the decorated and blended material deposits. Although the composition of the powders was identical for the decorated and blended $18 \mathrm{Ni}-10 \mathrm{Co}-72 \mathrm{WC}$, there was a much higher distribution of tungsten carbide in the deposit produced using powder where the soft phase is cladded to the hard phase compared to the deposit produced using blended powder. Data support the claim that nickel bonded to the surface of the core particle increases tungsten carbide retention in the coating.

Table 5. Comparison of coating hardness for tungsten carbide (WC)-based powders manufactured using different methods.

\begin{tabular}{ccc}
\hline Property & Decorated 18Ni-10Co-72WC & $\begin{array}{c}\text { Blended } \\
\mathbf{1 8 \% ~ N i ~ + ~ W C - C o ~}\end{array}$ \\
\hline Average Hardness (Vickers) & $789 \mathrm{HV}$ & $428 \mathrm{HV}$ \\
\hline
\end{tabular}

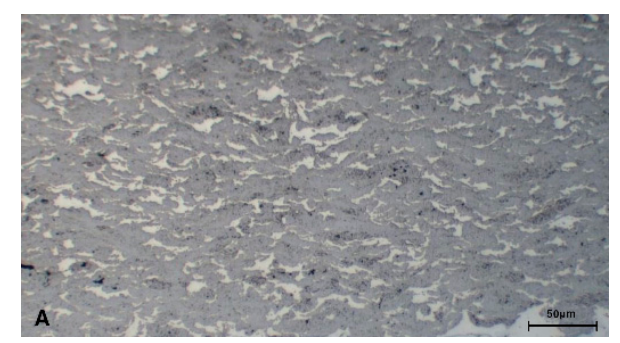

Figure 5. Cross-sections of cold spray deposits:

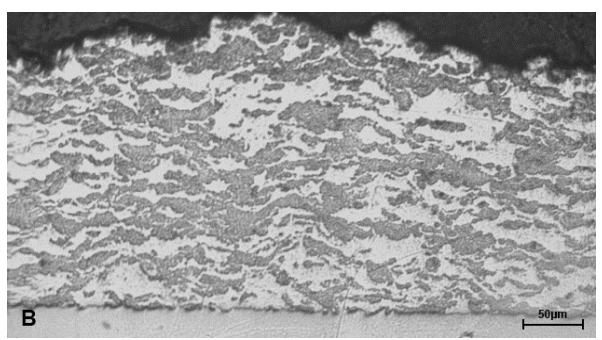

(A) decorated $18 \mathrm{Ni}-10 \mathrm{Co}-72 \mathrm{WC}$;

(B) blended $18 \mathrm{Ni}-10 \mathrm{Co}-72 \mathrm{WC}$.

Further analysis of the decorated powder using scanning electron microscopy revealed a key surface characteristic of particle agglomerates which contributes to improved coating quality. Figure 6 shows an SEM image of powder, where lighter areas correspond to a tungsten carbide-cobalt core particle and the darker areas correspond to regions of nickel. Nickel satellites are bonded to the tungsten carbide-cobalt core particle; this morphology is characteristic of both the standard and the $\beta$-trial powders. When the powder is cold sprayed at high velocities, deformation of the nickel allows for both the soft and hard phases to be deposited. Due to the solid bridge between the nickel and tungsten carbide, a higher tungsten carbide composition is achieved during consolidation compared to blending, resulting in a harder coating. EDS data of a coating in Figure 7 reveal a nickel concentration of $22 \mathrm{wt} . \%$, which corresponds to $78 \mathrm{wt} . \% \mathrm{WC}-\mathrm{Co}$ retention by subtraction. The nickel concentration in the coating moderately matches the nickel concentration of the powder; the difference is likely due to inaccuracies in EDS as a quantification method. This suggests that there is minimal bias towards soft phase consolidation, which indicates that tungsten carbide retention and correlated hardness is maximized. 


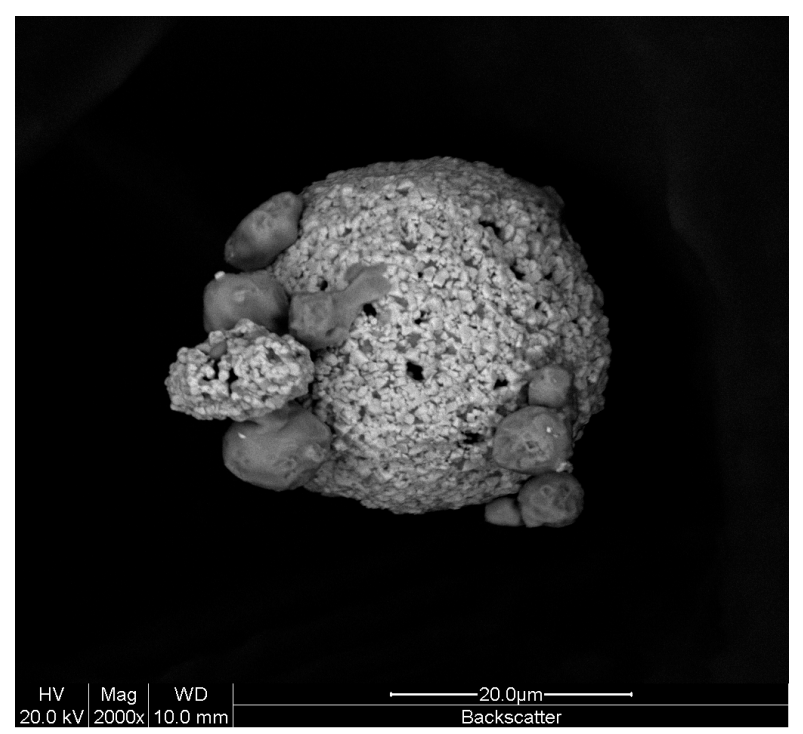

Figure 6. SEM backscatter image of decorated $18 \mathrm{Ni}-10 \mathrm{Co}-72 \mathrm{WC}$ at $2000 \times$.
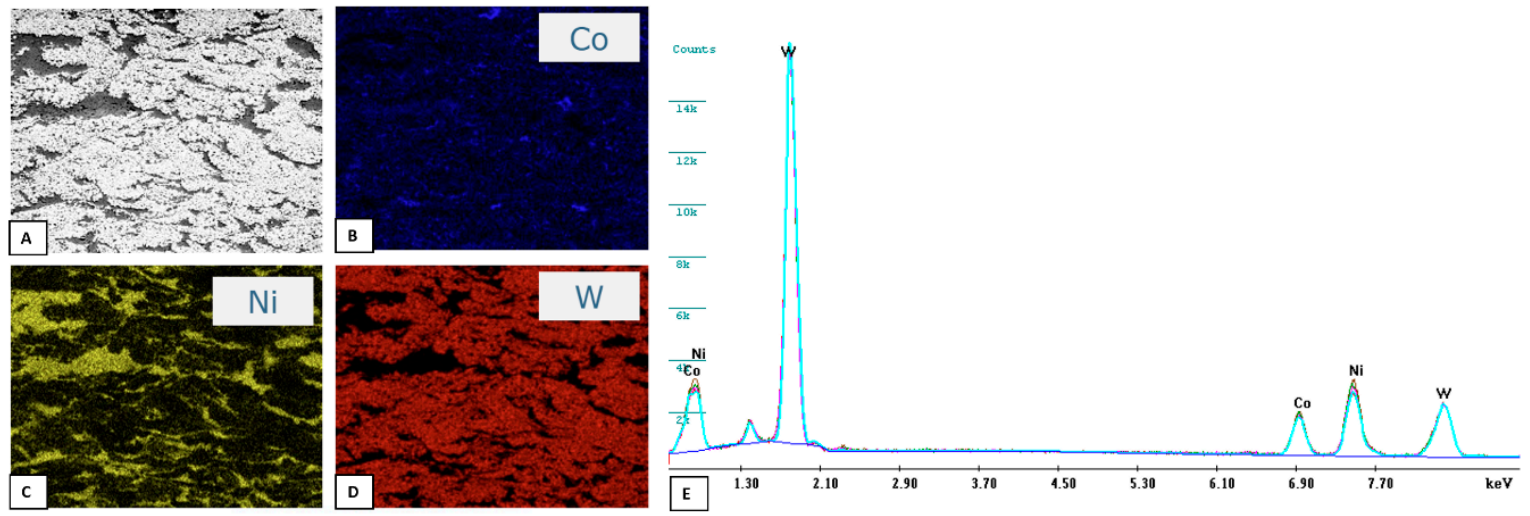

Figure 7. EDS map and spectra overlay of consolidated coupon cold sprayed using decorated $18 \mathrm{Ni}-10 \mathrm{Co}-72 \mathrm{WC}$. (A): secondary electron image of coating cross section; (B): cobalt EDS map; (C): nickel EDS map; (D): tungsten EDS map; (E) spectra overlay.

Table 5 shows the measured hardness for both coatings. The decorated $18 \mathrm{Ni}-10 \mathrm{Co}-72 \mathrm{WC}$ resulted in a hardness of $789 \mathrm{HV}$ compared to the $428 \mathrm{HV}$ recorded for the coating produced with blended material. Additionally, the deposition efficiency of the decorated $18 \mathrm{Ni}-10 \mathrm{Co}-72 \mathrm{WC}$ compared to the blended material was approximately $29 \%$ and $16 \%$, respectively. This data substantiates the claim that a higher mass compacted value measured during powder characterization correlates to improved deposition efficiency. The higher hardness is attributed to greater retention of tungsten carbide due to improved soft/hard phase configuration of the feedstock powder. Both the high hardness and overall density of the coating established using powder where the soft phase is bonded to the surface of the hard phase justify the use of the material for applications that use hard-chrome plating. Future work will involve optimizing cold spray parameters to maximize deposition efficiency and improve coating adhesion, toughness, and hardness.

\section{Conclusions}

While hard-chrome plating possesses good material properties in a wide range of material pairs and part configurations, its toxic nature has led to work developing alternate materials, such as the WC-Co-Ni material examined in this study. These new solutions require intelligent optimization of materials, as factors such as constituent hardness, morphology, composition, manufacturing process, and cold spray parameters will all impact the material's overall performance. Tailoring these 
parameters will allow for optimization of not only wear performance but also coating toughness and strain tolerance, even in fatigue environments. Powders synthesized with finer, soft-phase particles bonded to the outer surface of larger, hard-phase particles were compared against powders produced using traditional blending methods where the soft and hard phases are not physically attached. Feedstock powders were characterized for particle size distribution, density, flowability, and impact, which allow for a greater understanding of this material system. Cold spray depositions were evaluated for hardness and deposition efficiency and by optical microscopy to qualitatively analyze porosity and substrate/coating bond quality. The result was an optimized material of sufficient hardness and ductility for wear applications.

It was found that small changes in composition and particle morphology will have large effects on the final cold sprayed product. A balance was struck between the WC hard phase necessary for performance and the ductile nickel phase necessary for the sprayability of the final product. Particle configuration was also found to have a drastic effect on the final product, as powder with soft phase concentrated at the surface of a particle was found to have a hardness of $789 \mathrm{HV}$ vs. $428 \mathrm{HV}$ for a blended product where the soft phase was not physically bonded to the hard phase. It was also demonstrated that two cold spray nozzles could be used to deposit these materials, effectively opening the potential for more complex and smaller substrate geometries. The results presented here indicate that when nickel concentration, nozzle, and spray parameters are optimized, a material of sufficient hardness and deposition efficiency and minimal porosity can be produced. This material can be used in many of the hard-chrome plating applications, an important step in replacing a material with damaging environmental and health effects. In future work, additional studies evaluating the fracture toughness and wear resistance compared to standard materials will enhance the understanding of the applications for this material.

Author Contributions: Conceptualization, J.H., S.M.L., and C.W.; methodology, A.N., A.B., J.H., and M.S.; validation, R.B., J.H., M.S., and T.L.; formal analysis, J.H., S.M.L., and M.S.; investigation, R.B., J.H., M.S., and T.L.; resources, J.H., A.B., M.S., T.L., and R.B.; data curation, J.H., M.S., R.B., and S.M.L.; writing-original draft preparation, J.H., S.M.L., and C.W.; writing-review and editing, A.B., J.H., S.M.L., A.N., M.S., and C.W.; visualization, J.H.; supervision, A.B. and A.N.; project administration, A.B., J.H., A.N., and M.S.; funding acquisition, A.B. All authors have read and agreed to the published version of the manuscript.

Funding: This work was funded by the United States Army Research Laboratory, Grant \# W911NF-19-2-0155.

Conflicts of Interest: The authors declare no conflict of interest.

\section{References}

1. Vencl, A.; Gligorijević, B.; Katavić, B.; Nedić, B.; Džunić, D. Abrasive Wear resistance of the iron-and WC-based hardfaced coatings evaluated with scratch test method. Tribol. Ind. 2013. Available online: Www.tribology.fink.rs (accessed on 21 October 2020).

2. Monga, A.; Gumber, S.; Grover, H. Study of abrasion wear and factors affecting wear rate. Int. J. Adv. Res. Sci. Eng. 2018, 7, 113-120.

3. Kato, K.; Adachi, K. 7.1 Wear mechanisms. In Modern Tribology Handbook; CRC Press: Boca Raton, FL, USA, 2001; pp. 273-300.

4. Rohatgi, P.K.; Tabandeh-Khorshid, M.; Omrani, E.; Lovell, M.R.; Menezes, P.L. Tribology of metal matrix composites. In Tribology for Scientists and Engineers: From Basics to Advanced Concept; Springer: New York, NY, USA, 2013; pp. 233-268. ISBN 9781461419457.

5. He, X.; Ngo, D.; Kim, S. Mechanochemical Reactions of Adsorbates at Tribological Interfaces: Tribopolymerizations of Allyl Alcohol Coadsorbed with Water on Silicon Oxide. Langmuir 2019, 35, 15451-15458. [CrossRef] [PubMed]

6. Yamagata, H. The piston ring. Sci. Technol. Mater. Automot. Engines 2005, 1, 87-109. [CrossRef]

7. Fedrizzi, L.; Rossi, S.; Bellei, F.; Deflorian, F. Wear-corrosion mechanism of hard chromium coatings. Wear 2002, 253, 1173-1181. [CrossRef]

8. Widener, C.A.; Ozdemir, O.C.; Carter, M. Structural repair using cold spray technology for enhanced sustainability of high value assets. Procedia Manuf. 2018, 21, 361-368. [CrossRef] 
9. Astanin, V.K.; Pukhov, E.V.; Stekolnikov, Y.A.; Emtsev, V.V.; Golikova, O.A. Hardening parts by chrome plating in manufacture and repair. IOP Conf. Ser. Mater. Sci. Eng. 2018, 327, 032008. [CrossRef]

10. Czerwinski, F. Thermochemical treatment of metals. In Heat Treatment-Conventional and Novel Applications; IntechOpen: London, UK, 2012; pp. 73-112.

11. Shanker, A.K.; Venkateswarlu, B. Chromium: Environmental pollution, health effects and mode of action. In Encyclopedia of Environmental Health; Elsevier BV: Amsterdam, The Netherlands, 2011; pp. 650-659.

12. Juhani, K.; Pirso, J.; Viljus, M.; Letunovitš, S. Impact wear of chromium carbide based cermets. Mat. Sci. 2008, 14, 341-344.

13. Zikin, A.; Hussainova, I.; Katsich, C.; Badisch, E.; Tomastik, C. Advanced chromium carbide-based hardfacings. Surf. Coat. Technol. 2012, 206, 4270-4278. [CrossRef]

14. Fernandez, R.; Jodoin, B. Effect of particle morphology on cold spray deposition of chromium carbide-nickel chromium cermet powders. J. Therm. Spray Technol. 2017, 26, 1356-1380. [CrossRef]

15. Sidik, M.H.I.; Amir, N.; Kamal, S. Wear mechanism of wear resistant HVOF thermal spray coating: Chromium carbide nickel chrome on 304 AISI steel. MATEC Web Conf. 2018, 225, 06017. [CrossRef]

16. Castro, R.; Cavaler, L.; Marques, F.; Bristot, V.; Rocha, A. Comparative of the tribological performance of hydraulic cylinders coated by the process of thermal spray hvof and hard Chrome Plating. Trib. Ind. 2014, 36, 79-89.

17. Sahraoui, T.; Fenineche, N.-E.; Montavon, G.; Coddet, C. Alternative to chromium: Characteristics and wear behavior of HVOF coatings for gas turbine shafts repair (heavy-duty). J. Mater. Process. Technol. 2004, 152, 43-55. [CrossRef]

18. Champagne, V.; Nardi, A.; Nault, I. Cold Spray Coatings for Cr and Ni Plating Replacement. Final Report to SERDP, Approved for Public Release. 2019. Available online: https:/www.serdp-estcp.org/content/ download/50651/497809/file/WP-2607\%20Final\%20Report.pdf (accessed on 13 November 2020).

19. Li, C.-J.; Li, W. Deposition characteristics of titanium coating in cold spraying. Surf. Coat. Technol. 2003, 167, 278-283. [CrossRef]

20. Gavras, A.G.; Lados, D.A.; Champagne, V.K.; Warren, R.J.; Singh, D. Small fatigue crack growth mechanisms and interfacial stability in cold-spray 6061 aluminum alloys and coatings. Met. Mater. Trans. A 2018, 49, 6509-6520. [CrossRef]

21. Sova, A.; Kosarev, V.F.; Papyrin, A.; Smurov, I. Effect of ceramic particle velocity on cold spray deposition of metal-ceramic coatings. J. Therm. Spray Technol. 2010, 20, 285-291. [CrossRef]

22. Cizek, J.; Vilémová, M.; Lukáč, F.; Koller, M.; Kondás, J.; Singh, R. Cold sprayed tungsten armor for tokamak first wall. Coatings 2019, 9, 836. [CrossRef]

23. Bailly, O.; Laguionie, T.; Bianchi, L.; Vardelle, M.; Vardelle, A. Residual Stress Measurements in Cold Sprayed Tantalum Coatings. In Proceedings of the International Thermal Spray Conference and Exposition (ITSC), Houston, TX, USA, 21-24 May 2012; pp. 21-24.

24. Koivuluoto, H.; Coleman, A.; Murray, K.; Kearns, M.; Vuoristo, P. High pressure cold sprayed (HPCS) and low pressure cold sprayed (LPCS) coatings prepared from OFHC Cu feedstock: Overview from powder characteristics to coating properties. J. Therm. Spray Technol. 2012, 21, 1065-1075. [CrossRef]

25. Anupam, A.; Kumar, S.; Chavan, N.M.; Murty, B.S.; Kottada, R.S. First report on cold-sprayed AlCoCrFeNi high-entropy alloy and its isothermal oxidation. J. Mater. Res. 2019, 34, 796-806. [CrossRef]

26. Champagne, V.; Helfritch, D. Critical Assessment 11: Structural repairs by cold spray. Mater. Sci. Technol. 2014, 31, 627-634. [CrossRef]

27. Kang, S.H.; Park, D.H.; Choi, B.K.; Noh, S.; Kim, T.K. Spray of mechanically alloyed F/M-ODS steel powder. In Proceedings of the Korean Nuclear Society Spring Meeting, Jeju, Korea, 11-13 May 2016; pp. 1-2.

28. Moridi, A.; Hassani-Gangaraj, S.M.; Guagliano, M.; Dao, M. Cold spray coating: Review of material systems and future perspectives. Surf. Eng. 2014, 30, 369-395. [CrossRef]

29. Pathak, S.; Saha, G.C. Development of sustainable cold spray coatings and 3D additive manufacturing components for repair/manufacturing applications: A critical review. Coatings 2017, 7, 122. [CrossRef]

30. Lioma, D.; Sacks, N.; Botef, I. Cold gas dynamic spraying of WC-Ni cemented carbide coatings. Int. J. Refract. Met. Hard Mater. 2015, 49, 365-373. [CrossRef]

31. Nunthavarawong, P.; Sacks, N.; Botef, I. Effect of powder feed rate on the mechanical properties of WC-5 wt.\% Ni coatings deposited using low pressure cold spray. Int. J. Refract. Met. Hard Mater. 2016, 61, 230-237. [CrossRef] 
32. Melendez, N.; Narulkar, V.; Fisher, G.; McDonald, A.G. Effect of reinforcing particles on the wear rate of low-pressure cold-sprayed WC-based MMC coatings. Wear 2013, 306, 185-195. [CrossRef]

33. Alidokht, S.; Manimunda, P.; Vo, P.; Yue, S.; Chromik, R. Cold spray deposition of a Ni-WC composite coating and its dry sliding wear behavior. Surf. Coat. Technol. 2016, 308, 424-434. [CrossRef]

34. Melendez, N.; McDonald, A.G. Development of WC-based metal matrix composite coatings using low-pressure cold gas dynamic spraying. Surf. Coat. Technol. 2013, 214, 101-109. [CrossRef]

35. ISO 13322-1. Particle Size Analysis_Image Analysis Methods_Part 1: Static Image Analysis Methods; International Organization for Standards: Geneva, Switzerland, 2019; Available online: www.iso.org (accessed on 11 November 2020).

36. ASTM B964-16. Standard Test Methods for Flow Rate of Metal Powders Using the Carney Funnel; ASTM International: West Conshohocken, PA, USA, 2016; Available online: www.astm.org (accessed on 11 November 2020).

Publisher's Note: MDPI stays neutral with regard to jurisdictional claims in published maps and institutional affiliations.

(C) 2020 by the authors. Licensee MDPI, Basel, Switzerland. This article is an open access article distributed under the terms and conditions of the Creative Commons Attribution (CC BY) license (http://creativecommons.org/licenses/by/4.0/). 